\title{
Cannibalistic siblicide in praying mantis nymphs (Miomantis caffra)
}

\author{
Murray P. Fea $\cdot$ Margaret C. Stanley $\cdot$ \\ Gregory I. Holwell
}

Received: 6 February 2013/ Accepted: 1 November 2013/Published online: 22 November 2013

(C) Japan Ethological Society and Springer Japan 2013

\begin{abstract}
Inclusive fitness theory predicts that cannibalism should be more likely to arise if close relatives can be avoided, suggesting that cannibalistic species will possess mechanisms for minimizing predation on kin. Juvenile Miomantis caffra are good candidates for the possession of such traits because; (1) groups of siblings hatch together into the same locale, (2) they are aggressive hunters, and (3) they are strongly cannibalistic. In this study, the possibility of kin recognition or avoidance in $M$. caffra is investigated by laboratory comparison of cannibalism rates between groups of differing relatedness. In order to examine the likelihood of encounters between early instar siblings, the extent of dispersal away from the ootheca in the days following hatching is also observed. Nymphs did not rapidly disperse after hatching, so the chances of full siblings encountering one another in the wild appear to be high. Despite this, cannibalism was equally high in groups of full siblings and groups of mixed parenthood. We suggest that for $M$. caffra, a generalist ambush predator, the benefits of indiscriminate aggression may outweigh any inclusive fitness benefits that would be gained from kin discrimination.
\end{abstract}

Keywords Cannibalism $\cdot$ Kin selection $\cdot$ Kin recognition · Mantodea

M. P. Fea · M. C. Stanley · G. I. Holwell ( $₫)$

School of Biological Sciences, The University of Auckland,

Auckland 1142, New Zealand

e-mail: g.holwell@auckland.ac.nz

\section{Introduction}

Many biological traits can be understood more clearly in the light of kin selection theory (Mock and Parker 1998), which demonstrates how individuals may increase their total fitness by aiding their relatives, due to the high proportion of genes shared among them (Hamilton 1964; West and Gardner 2010). This may facilitate the evolution of altruistic behavior (e.g., Nam et al. 2010). Hamilton (1964) highlighted two ways in which kin selection may act, through kin recognition or high population viscosity.

Although most studies testing kin selection theory focus on the helping of kin, in regard to intraspecific aggression, theory predicts that increasing its rate across all members of a population must decrease the expected survival of all individuals, inducing a necessary inclusive fitness cost (Nishimura and Isoda 2004). Therefore, a trait to which inclusive fitness theory is directly relevant is siblicide, which occurs in many species (Mock and Parker 1998), and in some cases even appears to be an obligate behavior (e.g., Anderson 1990).

Kin recognition, the ability to distinguish relatives from non-relatives, allows discrimination to be displayed in the behavior of the organism such that relatives are favored over non-relatives (Murphy and Dudley 2009). Recognition of relatives can occur in several ways (Tsutsui 2004), including self-referential (Gerlach and Lysiak 2006; Mateo 2010) and direct genetic (Rousset and Roze 2007) phenotypic matching as well as learning cues associated with siblings and parents during early development and then retaining this information in order to identify those individuals later in life (Gerlach et al. 2008; Sharp et al. 2005). In some cases, a combination of these may be used (e.g., Newey 2010).

Recognition may, however, not be essential for kin discrimination if population viscosity is high, because 
interacting individuals are more likely to be related simply by chance than in populations of more dispersive organisms (Gardner 2010; Hamilton 1964). This would mean that altruistic acts towards conspecific neighbors would garner greater benefits to inclusive fitness, and make the evolution of indiscriminate helping of others more likely (Lion and Gandon 2010). However, high population viscosity also has the effect of increasing local resource competition between related individuals, which has been shown in analytical models to counteract the positive fitness effects of kin selection (Queller 1994; Taylor 1992). This may provide the circumstances for altruism to be selected against even if it would seem proximally beneficial. For example, West et al. (2001) showed that, in many species of fig wasp, males enclosed in fruit fought each other to varying degrees independently of relatedness, and instead in response to the scarcity of females. Therefore, in populations with limited dispersal and competition for resources, we may expect altruism not to be expressed even when related individuals commonly interact.

Siblicide has been well studied in avian taxa, species with parental provisioning, and some spiders (Bilde and Lubin 2001), but experimental data from other groups are needed to fully understand its evolution (Dobler and Kölliker 2010; Ento et al. 2010). Predation upon conspecific individuals also occurs across a broad array of other animal taxa (Agarwala and Dixon 1992), including amphipods (Duarte et al. 2010), insects (e.g., Dobler and Kölliker 2010), snails (Nicolai et al. 2010), frogs (Pfennig and Frankino 1997), and fish (Myint et al. 2010). This behavior is acknowledged to improve survival of the actor, to occur more frequently when alternative prey are scarce, and to act as a population regulatory mechanism (Agarwala and Dixon 1992; Getto et al. 2005; Polis 1981). This is germane to inclusive fitness theory because of the obvious relevance of consuming offspring to reproductive success, and of consuming siblings to inclusive fitness.

Praying mantises represent an excellent model for assessing this system. They have been shown to have high mortality due to starvation in the field (Hurd and Eisenberg 1984), they occur at high densities post-hatching, and cannibalism is commonly observed among praying mantis nymphs in both the field and the laboratory (Fagan and Odell 1996; Hurd 1988).

Here, we test for kin discrimination in the praying mantis Miomantis caffra, native to South Africa (Ramsay 1990), as well as checking for an effect of size asymmetry in nymphs, since this is a factor strongly implicated in cannibalism among a range of organisms (Dobler and Kölliker 2010; Michaud 2003; Samu et al. 1999).

The objective of this paper is to test for the possibility of kin recognition in $M$. caffra nymphs, by observing cannibalism among groups comprised entirely of siblings and comparing it with that in groups comprised of nymphs from two broods. The influence of relative body mass on this behavior is also of interest in this context, as siblings may co-occur in mixed groups of first and second instars due to differential growth within a clutch. If siblings avoid attacking each other even when there is a size difference (and risk is therefore low for the larger nymph), then it would add weight to the conclusion that they display discrimination against attacking kin. Therefore, cannibalism rates are examined here in groups of siblings and nonsiblings comprised of both similarly sized and differently sized individuals, factors rarely considered together in one experiment (but see Dobler and Kölliker 2011). Because the importance of these traits is expected to be strongly influenced by the likelihood of encounters between nymphs, the number of hatchling nymphs that remain close to each other in a natural setting is also monitored.

\section{Materials and methods}

\section{Maintenance}

Oothecae were produced in the laboratory by wild-caught M. caffra females over the period March-June 2010. These females were kept on a maintenance diet of Galleria mellonella larvae (Lepidoptera), Tenebrio molitor larvae (Coleoptera), Locusta migratoria juveniles (Orthoptera), Drosophila melanogaster adults (Diptera, flightless morph), Sitophilus oryzae adults (Coleoptera), Exaireta spinigera larvae (Diptera), and Plodia interpunctella larvae (Lepidoptera). The laboratory-laid oothecae were supplemented by 20 wild-gathered egg cases to increase the availability of nymphs; these were mixed randomly and not in any way distinguished from the others throughout the study. When clutches began to hatch (in September 2010), they were split into fed and non-fed groups of siblings (siblings classed as those nymphs to have hatched from the same ootheca, ensuring at least maternal relatedness, although paternity was unknown) to create a within-brood size difference. Nymphs of the fed groups were allowed to prey ad libitum on D. melanogaster (flightless morph), those of unfed groups were not given any alternative prey, but some cannibalism may have occurred. Both fed and unfed nymphs were misted with water daily.

Assessment of post-hatching dispersal

In order to estimate the natural density of nymphs that occurs near hatching oothecae in the wild, the following procedures were carried out. A 1.8-m-tall Kowhai (Sophora microphylla) sapling was cleared of any spider webs and wild mantis nymphs or oothecae. This tree was situated 
outdoors, growing in the soil rather than a container, and in close proximity to grasses and other plants. To simulate a hatching event, 10 newly hatched, sibling nymphs from only laboratory-laid oothecae were placed at the plant's center and the site of release was marked. This was replicated six times, using the same sapling sequentially. Ten nymphs were chosen because most emergences of $M$. caffra nymphs observed in the laboratory consisted of approximately that many individuals.

Once each day over the following 5 days, a 10-min search was carried out and the distance of each nymph found from the point of release was measured. It is important to note that the purpose of this search was not to locate and count every nymph present on the tree, but to provide a point of reference between days. Therefore, only an estimate of their change in numbers was gained, rather than a count of the total present. The mean number of nymphs recounted, and the mean distance of all nymphs from their release point on each day, were calculated. The differences in number and distance of nymphs between the first and last days were both found to be non-normally distributed using the Jarque-Bera normality test (JB $=0.425, \quad P=0.809$, and $\mathrm{JB}=0.288, \quad P=0.866$, respectively). Therefore, they were compared using MannWhitney tests.

\section{Cannibalism experiments}

Treatment groups were set up with the following combinations: (1) 10 sibling nymphs from the same brood, $n=15$; (2) 5 nymphs from 1 brood and 5 from another, $n=16$; (3) 5 larger nymphs from a fed group and 5 smaller nymphs from a non-fed group of the same brood, $n=15$; and (4) 5 larger nymphs from a fed group and 5 smaller nymphs from a non-fed group of different broods, $n=16$. A subsample of these different-sized nymphs had a mean pronotum length of $2.218 \pm 0.18 \mathrm{~mm} \mathrm{SE}(n=16)$ in "large" nymphs and $1.288 \pm 0.06 \mathrm{~mm} \mathrm{SE}(n=16)$ in small nymphs. Each set of 10 nymphs was placed into an approximately $30 \times 30 \times 30 \mathrm{~cm}$ enclosure made of fine mesh screen, with a polyurethane window. These were misted with water daily; no food was provided.

The number of surviving and dead nymphs was counted each day for 10 days. Any dead nymphs were inspected under a Leica ${ }^{\circledR}$ MZ6 dissecting microscope for signs of cannibalism. If they were dismembered, had puncture wounds, or were missing parts of the abdomen, thorax, or head then they were counted as cannibalized, otherwise as having died of other causes. Loss of one limb or antennae was considered possible through complications with ecdysis, so only those with more than one missing appendage were counted as cannibalized. Any molted cuticle was removed from the enclosures daily. Nymphs were counted before and after opening the enclosures to ensure no escapes occurred; none were unaccounted for, so any missing (i.e., not counted as dead or surviving) were presumed to have been completely cannibalized. The mean number of nymphs to be cannibalized on each day was calculated for each group type. Normality of distributions was not found in any of the four groups using Jarque-Bera tests $(\mathrm{JB}=1.5, P=0.47, \mathrm{JB}=2.4, P=0.3, \mathrm{JB}=2.46$, $P=0.292$, and $\mathrm{JB}=1.67, P=0.434)$. Therefore, the Kruskal-Wallis non-parametric ANOVA was used to test the null hypothesis that the samples were taken from populations with equal medians. This included pair-wise two-tailed Mann-Whitney tests made between each group for each day. To compare nymphs differing in relatedness or size disparity independently, groups were pooled with respect to one of these and compared using Mann-Whitney tests. To account for an increased probability of type-1 statistical errors when performing multiple tests, we used the Benjamini-Hochberg $(\mathrm{B}-\mathrm{H})$ test for false discovery rate to adjust the critical cut-offs for statistically significant $P$ values. All tests were carried out using the statistics package PASTC) v.2.08 (Hammer et al. 2001).

\section{Results}

Assessment of post-hatching numbers

Upon release onto the plant, nymphs typically moved several $\mathrm{cm}$ upwards on the main stem until they reached the underside of a leaf. During this initial dispersal, nymphs often encountered one another, sometimes clambering over their siblings to proceed up the branch. Nymphs were successfully recounted on each day, often being found in the exact same location. During counting, it was noted that many nymphs remained in the same position from day to day, so the number of nymphs to remain on the same compound leaf for three or more consecutive days was counted. Although possible, we considered it highly unlikely that nymphs would have swapped positions perfectly and so interfered with this count. The number of nymphs that could be recounted reduced gradually over time, and, at the end of 5 days, there were still $3.2 \pm 0.6$ visible nymphs on average, with a maximum of 5 and a minimum of 1 . The nymphs that were recounted $(n=34)$ moved a mean distance from the release site of only $26.7 \pm 0.940 \mathrm{~cm}$, and 18 of those maintained zero change in position for $\geq 3$ consecutive days. There was no significant difference between the number of nymphs recounted on the first $(n=34)$ and last $(n=21)$ day of counts ( $U=7.5$; effect size $r=0.472 ; P=0.102)$ or their distance from the starting location $(U=328.5$; effect size $r=0.065 ; P=0.628)$. 


\section{Cannibalism experiments}

Cannibalism was commonly observed in both sibling and non-sibling enclosures, accounting for greater loss of nymphs than natural mortality in all treatments with the exception of the equally sized non-siblings (Table 1). Kruskal-Wallis ANOVA indicated that not all medians were equal among the samples $(\mathrm{Hc}=18.27, P<0.005)$, and Mann-Whitney tests followed by tests for false discovery rate indicated that significant differences in the extent of cannibalism occurred in all comparisons where one group was disparate in size and the other was not (Table 2).

The difference in the final number of nymphs cannibalized at the end of 10 days remained non-significant between enclosures of sibling and non-sibling nymphs when size difference groups were pooled ( $U=463$; effect size $r=0.03$; $P=0.809$; Fig. 1a). In addition, the mean number of nymphs that were cannibalized remained similar between relatedness groups throughout the 10-day period, with Mann-Whitney tests also failing to find a significant difference on any individual day (Fig. 2a) (day 1: $U=398, P=0.149$, day $2: U=425.5, P=0.414$, day 3 : $U=402, P=0.252$, day $4: U=409.5, P=0.31$, day 5 : $U=424.5, P=0.429$, day $6: U=421, P=0.3$, day 7 : $U=428, P=0.459$, day $8: U=429.5, P=0.473$, day 9: $U=434.5, P=0.517$, day $10: U=463, P=0.809)$. No test for false discovery rate was required as all comparisons were non-significant.

There was, however, a difference between final number cannibalized in same size and different-sized nymphs when relatedness was pooled, with enclosures that had a size difference showing a significantly higher level of cannibalism at the end of 10 days (Table 3). After testing for false discovery rate, all these differences remained highly significant.

This cannibalism was performed by large nymphs in all cases, as evidenced by counts of remaining large and small nymphs on each day. Despite this, however, there was still no significant difference in the final number cannibalized between combined sibling and non-sibling groups when there was also a size difference between nymphs $(U=97.5 ; r=0.177 ; P=0.378)$, the circumstance in which we might have expected cannibalism to be highest.

\section{Discussion}

We found that $M$. caffra nymphs seem to remain in close proximity to siblings. We also found that nymphs cannibalized siblings at similar levels to non-siblings, providing no evidence for kin recognition. Lastly, we also found a higher degree of cannibalism when groups of nymphs varied in size.

\section{Assessment of post-hatching dispersal}

Sharell (1971) observed $M$. caffra nymphs cannibalizing one another before dispersing from their hatching location, so they are known to do so as long as they remain within close proximity to each other. Because of this, the number
Table 1 Sources of mortality in each grouping of Miomantis caffra nymphs, based on relatedness and size difference

Initial group size $n=10$

\begin{tabular}{lllll}
\hline & $\begin{array}{l}\text { Equal-sized } \\
\text { siblings }\end{array}$ & $\begin{array}{l}\text { Different-sized } \\
\text { siblings }\end{array}$ & $\begin{array}{l}\text { Equal-sized } \\
\text { non-siblings }\end{array}$ & $\begin{array}{l}\text { Different-sized } \\
\text { non-siblings }\end{array}$ \\
\hline $\begin{array}{l}\text { Mean number } \\
\text { cannibalized } \pm \text { SE }\end{array}$ & $3.40 \pm 0.50$ & $5.07 \pm 0.45$ & $2.68 \pm 0.45$ & $5.63 \pm 0.61$ \\
$\begin{array}{c}\text { Mean number of natural } \\
\text { deaths } \pm \text { SE }\end{array}$ & $2.93 \pm 0.59$ & $2.43 \pm 0.52$ & $4.81 \pm 0.72$ & $2.13 \pm 0.51$ \\
\hline
\end{tabular}

Table 2 Comparisons between the extent of cannibalism in each group of $M$. caffra nymphs at the end of 10 days

\begin{tabular}{lllllcc}
\hline Comparison & $U$ & $r$ & $P$ & Index & B-H critical \\
\hline DS vs DN & 97.5 & 0.157 & 0.378 & 1 & 0.05 & Sig* \\
ES vs EN & 94.5 & 0.179 & 0.312 & 2 & 0.042 & 0.033 \\
ES vs DS & 57.5 & 0.418 & 0.022 & 3 & 0.025 & $*$ \\
ES vs DN & 50.5 & 0.5 & 0.006 & 5 & 0.017 \\
DS vs EN & 42.5 & 0.554 & 0.002 & 6 & 0.008 & $*$ \\
EN vs DN & 39 & 0.602 & 0.001 & & $*$ \\
\hline
\end{tabular}

The B-H critical value is the adjusted significance threshold after accounting for false discovery rate using the Benjamini-Hochberg (B-H) procedure. Comparisons are deemed statistically significant $\left(\mathrm{Sig}^{*}\right)$ when $P$ is less than the B-H critical value and represented with an asterisk $(*)$ Index the order of increasing significance, $E S$ equal size siblings, $D S$ different size siblings, $E N$ equal size non-siblings, $D N$ different size nonsiblings 


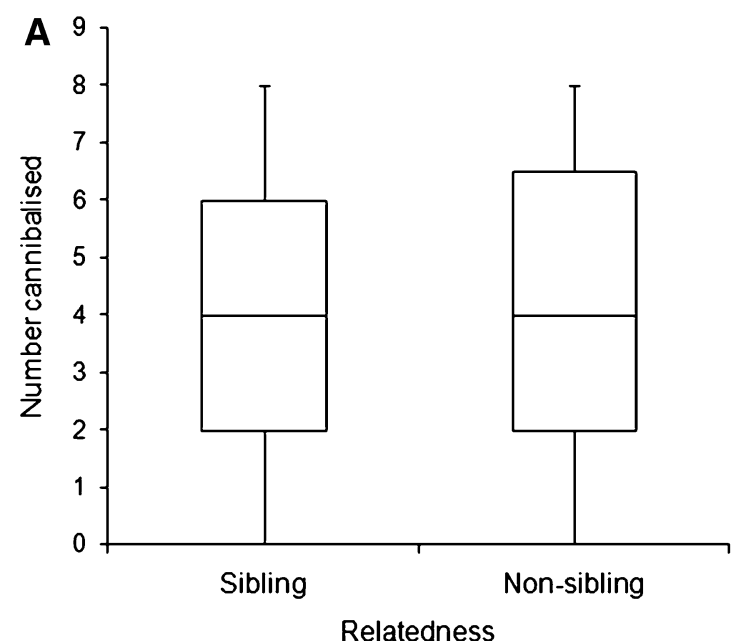

Fig. 1 Number of cannibalized nymphs of Miomantis caffra by the end of 10 days in sibling and non-sibling groups with size categories combined (a) and in same and different-sized groups, with relatedness combined (b). Horizontal bars represent the median number

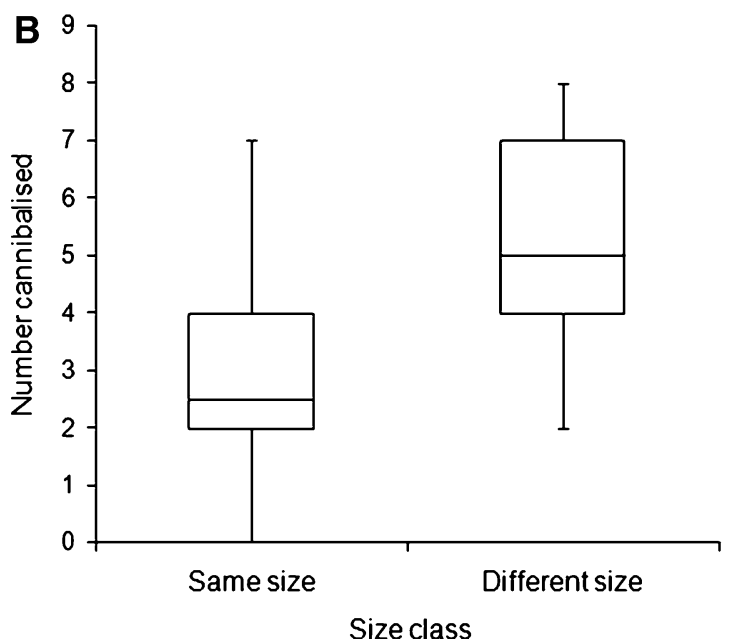

cannibalized, the upper and lower edges of boxes represent the third and first quartiles, respectively, and whiskers represent the maximum and minimum number cannibalized
Fig. 2 Cannibalism $( \pm$ SE) over time in enclosures containing sibling $(n=30)$ or non-sibling $(n=32)$ groups, regardless of size class (a), and in enclosures containing same $(n=31)$ or different-sized $(n=31)$ groups, regardless of relatedness (b).

Results which were statistically significant after correction for false discovery rate are indicated by asterisk

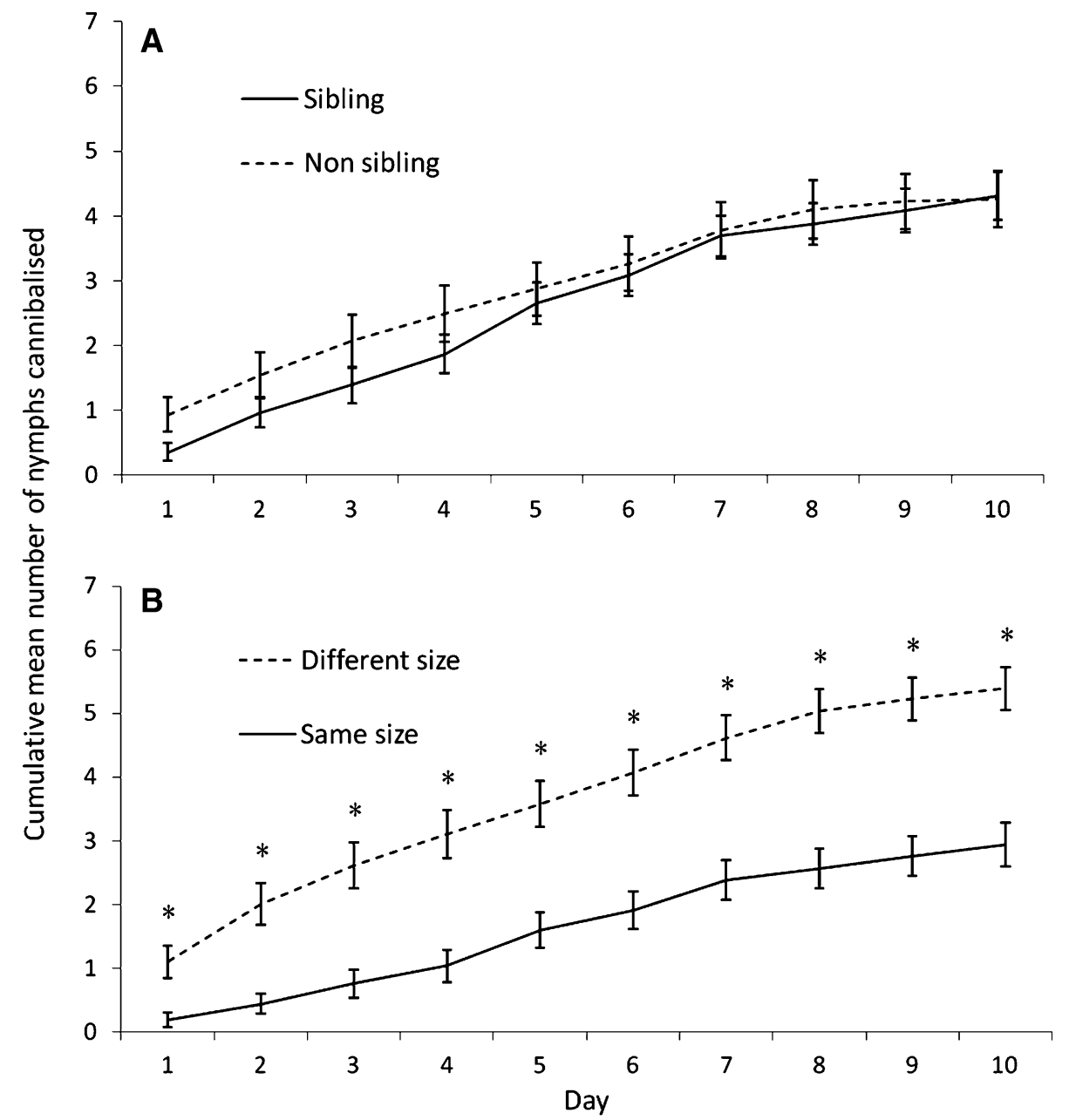


Table 3 Comparisons between the extent of cannibalism of same size and different-sized groupings of $M$. caffra nymphs from day 1 to day 10

\begin{tabular}{lllllll}
\hline Comparison & $U$ & $r$ & $P$ & Index & B-H critical & Sig* \\
\hline Day 1 & 300.5 & 0.595 & 0.0008 & 1 & 0.05 & $*$ \\
Day 2 & 211.5 & 0.737 & 0.0005 & 2 & 0.045 & $*$ \\
Day 3 & 221 & 0.695 & 0.0005 & 3 & 0.04 & $*$ \\
Day 4 & 213.5 & 0.702 & 0.0005 & 4 & 0.035 & $*$ \\
Day 5 & 221.5 & 0.675 & 0.0001 & 10 & 0.005 & $*$ \\
Day 6 & 198.5 & 0.732 & 0.0005 & 5 & 0.03 & $*$ \\
Day 7 & 191.5 & 0.747 & 0.0005 & 6 & 0.025 & $*$ \\
Day 8 & 175.5 & 0.785 & 0.0005 & 7 & 0.02 & $*$ \\
Day 9 & 173.5 & 0.792 & 0.0005 & 8 & 0.015 & $*$ \\
Day 10 & 189.5 & 0.752 & 0.0005 & 9 & 0.01 & $*$ \\
\hline
\end{tabular}

The B-H critical value is the adjusted significance threshold after accounting for false discovery rate using the Benjamini-Hochberg (B-H) procedure. Comparisons are deemed statistically significant (Sig*) when $P$ is less than the B-H critical value and represented with an asterisk $(*)$

Index the order of increasing significance

of nymphs remaining near their hatching location is pertinent to our predictions about kin selection and cannibalism in this species. The slow reduction in nymph abundance on the test plant suggests that they tend to remain numerous near the ootheca after hatching. The lack of movement observed for many nymphs, as well as their near-constant average distance from the release point over time, indicate that they are not naturally dispersive and that the reduction in numbers was more likely to be due to mortality. The actual number remaining was probably higher than that recorded by the researcher, due to the nymphs being small and cryptic in coloration and behavior. Therefore, these represent conservative estimates of nymph numbers. The estimate of Ramsay (1990) of approximately 100 nymphs emerging from each ootheca over a 4-month hatching period, and the number of nymphs to remain close to the ootheca observed presently, suggests that their density should tend to increase throughout the hatching period, with many nymphs within around $30 \mathrm{~cm}$ of the ootheca on any given day during that time. This local density of nymphs around hatching oothecae makes encounters between early-instar juveniles likely, thus providing the opportunity for aggression between siblings.

In addition to the low dispersal observed here, we expect the usual density of nymphs around their parent ootheca to be high in this species for several reasons: (1) over 100 nymphs can hatch from each egg case (Ramsay 1990), often in batches of 5-20 at a time (personal observation); (2) the ootheca is fixed in position, unlike some insects which carry or periodically move them about (e.g., Blattodea sp.; Bell et al. 2007), so all the nymphs hatch into the same area; (3) they are unable to fly until reaching adulthood, which is not usually for around 5 months and even then only in males (Ramsay 1990); and (4) they are cryptic, ambush hunters and therefore spend a large proportion of their time awaiting prey while stationary.

\section{Cannibalism}

The nymphs of $M$. caffra did not show kin-biased discrimination in their cannibalistic behavior in this study, despite the seemingly high likelihood of encounters between siblings after hatching. The non-overlapping generations of $M$. caffra (Ramsay 1990), make siblings the closest relatives they will ever encounter. Therefore, from the perspective of inclusive fitness theory, the lack of discrimination against attacking relatives in nymphs of this species is surprising.

This is in contrast to studies that have found that discrimination does occur in other cannibalistic arthropod species. For example, in the lady bug, Adalia bipunctata, juveniles were shown to discriminate between kin and nonkin when cannibalizing unhatched eggs (Agarwala and Dixon 1993). Kin recognition and lower rates of siblicidal cannibalism among juvenile wolf spiders have also been demonstrated for Hogna helluo (Roberts et al. 2003), but not for Pardosa amentata (Hvam et al. 2005) or Pardosa pseudoannulata (Iida 2003), revealing that the relationship between kin recognition and cannibalism is far from universal.

The nymphs of $M$. caffra did not cannibalize non-siblings any more than siblings, even when there was a size difference between them and cannibalism should have been a low-risk strategy, thus supporting the suggestion that they do not bias their intraspecific predation efforts away from relatives. This is interesting, because mantids will be more likely to encounter relatives than non-relatives due to their hatching proximity, and a lack of kin-discrimination would result in greater mortality of relatives (Getto et al. 2005). This is especially so if, as found in another species (Fagan and Folarin 2001), M. caffra deposit oothecae in a spatially clustered manner.

Relative body mass can affect the occurrence of both siblicidal and cannibalistic behavior (Hvam et al. 2005; Polis 1981), and a size difference reduces the inherent risk for the larger individual in attacking a conspecific (Rudolf et al. 2010). Therefore, we should expect cannibalism to be more prevalent in groups of nymphs within which there is some variation in size (Crumrine 2010). In our study, comparisons of the degree of cannibalism between groups exhibiting a size difference were significant with all producing medium to large effect sizes. The increased prevalence of cannibalism in enclosures with size variation observed here supports the findings of studies which have shown within-cohort body mass differences to influence 
cannibalism in other juvenile insects (e.g., Crumrine 2010; Lounibos et al. 1996), including the praying mantis, Tenodera angustipennis (Fagan and Odell 1996).

\section{Lack of kin discrimination}

There are three likely mechanisms for reducing intra-brood cannibalism which might be employed by a species such as M. caffra: recognition and avoidance of kin, rapid dispersal from the oothecae, and asynchronous hatch phenology. None of these mechanisms appear to be operating in $M$. caffra to reduce siblicide. Therefore, it appears that $M$. caffra may lack the discrimination to reduce within-brood cannibalism. Since inclusive fitness theory clearly predicts that cannibalism of siblings should be avoided if possible (Anthony 2003; Hamilton 1964), the lack of any discrimination in the juveniles of this species raises questions as to why siblicide has not been selected against.

A possible explanation is that parents often produce more offspring than they or the environment can provide for, necessitating a negative regulation on the local population during development (Mock and Parker 1998), termed brood reduction (O'Connor 1978). This seemingly wasteful oversupply may actually be beneficial, as it allows exploitation of stochastic increases in resource availability (e.g., Sergio et al. 2010), the ability of some offspring to provide essential nutrients to their siblings through cannibalism and for killed or injured members of the brood to be replaced, so that optimal density is maintained (Mock and Parker 1998). This bet-hedging strategy equates to having some offspring on standby, in case conditions happen to support greater than usual density, or mortality is unusually high (Simons 2007).

In cases where kin cannibalism occurs, siblings can also be thought of as resource caches that autonomously gather more food for their clutch, returning it in the form of their own biomass (Polis 1981; Sherratt et al. 1999). This is an extension of the trophic egg concept which refers to the parental provisioning of offspring with unhatched siblings (Kim and Roland 2000). In some species, this can represent a major component of the diet, such as in black widow spiders, Latrodectus hasseltii, which can develop to within one molt of adulthood solely on the sustenance given by their unhatched sibling eggs (Kaston 1968).

An alternative reason for high rates of cannibalism in some species is aggressive spillover, or the selection for aggression levels which are necessary to ensure successful foraging but which are also displayed in other behavioral contexts (Arnqvist and Henriksson 1997; Johnson and Sih 2005). This is especially likely when aggression is beneficial during early developmental stages but then retained into adulthood (Johnson and Sih 2005; Morse 2004). This hypothesis has been supported by research on the fishing spider, Dolomedes triton, in which propensity for precopulatory sexual cannibalism is correlated with aggression levels displayed throughout development (Johnson 2001; Johnson and Sih 2005). This may apply to M. caffra if nymphs which indiscriminately attack and consume all potential prey are more likely to reach adulthood, regardless of whether it means killing siblings in the process, as found in the ladybirds Propylea dissecta and Coccinella transversalis (Pervez et al. 2005). This lack of plasticity in behavior can help explain several interesting and seemingly detrimental traits, such as adversely high levels of pre-copulatory cannibalism (Arnqvist and Henriksson 1997) or activity in the presence of predators (Maurer and Sih 1996).

Generalist ambush predators are frequently food-limited (Hurd 1988; Wise 2006), and the high risk of starvation for praying mantis nymphs is likely to select for their indiscriminately aggressive behavior. Considering the suggestion by models (Queller 1994; Taylor 1992) and some other experiments (Abe et al. 2005; West et al. 2001) that high resource competition between relatives should suppress kin selection, it seems probable that, for predators with a high risk of food-limitation, the possible inclusive fitness benefits of foregoing cannibalism of kin are outweighed by the risk of starvation, and the associated benefits of indiscriminate foraging.

Acknowledgments We would like to thank Angie Gibbons for donating specimens and the School of Biological Sciences, University of Auckland, for funding. We are grateful to anonymous reviewers for their very helpful feedback and comments on earlier versions of the manuscript.

\section{References}

Abe J, Kamimura Y, Shimada M (2005) Individual sex ratios and offspring emergence patterns in a parasitoid wasp, Melittobia australica (Eulophidae), with superparasitism and lethal combat among sons. Behav Ecol Sociobiol 57(4):366-373

Agarwala BK, Dixon AFG (1992) Laboratory study of cannibalism and interspecific predation in ladybirds. Ecol Entomol 17(4):303-309

Agarwala BK, Dixon AFG (1993) Kin recognition-egg and larval cannibalism in Adalia bipunctata. Eur J Entomol 90:45-50

Anderson D (1990) Evolution of obligate siblicide in boobies, I. A test of the insurance egg hypothesis. Am Nat 135:334-350

Anthony CD (2003) Kinship influences cannibalism in the wolf spider, Pardosa milvina. J Insect Behav 16(1):23-26

Arnqvist G, Henriksson S (1997) Sexual cannibalism in the fishing spider and a model for the evolution of sexual cannibalism based on genetic constraints. Evol Ecol 11(3):255-273

Bell W, Roth LM, Nalepa CA (2007) Cockroaches: ecology, behaviour and natural history. John Hopkins University Press, Baltimore

Bilde T, Lubin $\mathrm{Y}$ (2001) Kin recognition and cannibalism in a subsocial spider. J Evol Biol 14(6):959-966

Crumrine PW (2010) Body size, temperature, and seasonal differences in size structure influence the occurrence of cannibalism in 
larvae of the migratory dragonfly, Anax junius. Aquat Ecol 44(4):761-770

Dobler R, Kölliker M (2010) Kin-selected siblicide and cannibalism in the European earwig. Behav Ecol 21(2):257-263

Dobler R, Kölliker M (2011) Influence of weight asymmetry and kinship on siblicidal and cannibalistic behaviour in earwigs. Anim Behav 82(4):667-672

Duarte C, Jaramillo E, Contreras H, Acuña K (2010) Cannibalism and food availability in the talitrid amphipod Orchestoidea tuberculata. J Sea Res 64(3):417-421

Ento K, Araya K, Kudo SI (2010) Laboratory observation of siblicide with hatching asynchrony in an insect with parental provisioning. J Ethol 28(2):405-407

Fagan WF, Folarin A (2001) Contrasting scales of oviposition and parasitism in praying mantids. Popul Ecol 43(1):87-96

Fagan WF, Odell GM (1996) Size-dependent cannibalism in praying mantids: using biomass flux to model size-structured populations. Am Nat 147(2):230-268

Gardner A (2010) Sex-biased dispersal of adults mediates the evolution of altruism among juveniles. J Theor Biol 262(2):339-345

Gerlach G, Lysiak N (2006) Kin recognition and inbreeding avoidance in zebrafish, Danio rerio, is based on phenotype matching. Anim Behav 71(6):1371-1377

Gerlach G, Hodgins-Davis A, Avolio C, Schunter C (2008) Kin recognition in zebrafish: a 24-hour window for olfactory imprinting. Proc R Soc Lond B 275(1647):2165-2170

Getto P, Diekmann O, De Roos AM (2005) On the (dis) advantages of cannibalism. J Math Biol 51(6):695-712

Hamilton WD (1964) The genetical evolution of social behaviour. I. J Theor Biol 7(1):1-16

Hammer O, Harper DAT, Ryan PD (2001) PAST: paleontological statistics software package for education and data analysis. Palaeontol Electron 4(1):9

Hurd LE (1988) Consequences of divergent egg phenology to predation and coexistence in two sympatric, congeneric mantids (Orthoptera: Mantidae). Oecologia 76(4):549-552

Hurd LE, Eisenberg RM (1984) Experimental density manipulations of the predator Tenodera sinensis (Orthoptera: Mantidae) in an old-field community. I. Mortality, development and dispersal of juvenile mantids. J Anim Ecol 53(1):269-281

Hvam A, Mayntz D, Nielsen R (2005) Factors affecting cannibalism among newly hatched wolf spiders. J Arachnol 33:377-383

Iida H (2003) Small within-clutch variance in spiderling body size as a mechanism for avoiding sibling cannibalism in the wolf spider Pardosa pseudoannulata (Araneae: Lycosidae). Popul Ecol 45:1-6

Johnson JC (2001) Sexual cannibalism in fishing spiders (Dolomedes triton): an evaluation of two explanations for female aggression towards potential mates. Anim Behav 61(5):905-914

Johnson JC, Sih A (2005) Precopulatory sexual cannibalism in fishing spiders (Dolomedes triton): a role for behavioral syndromes. Behav Ecol Sociobiol 58(4):390-396

Kaston BJ (1968) Remarks on black widow spiders, with an account of some anomalies. Entomol News 79:113-124

Kim KW, Roland C (2000) Trophic egg laying in the spider, Amaurobius ferox: mother-offspring interactions and functional value. Behav Process 50(1):31-42

Lion S, Gandon S (2010) Life history, habitat saturation and the evolution of fecundity and survival altruism. Evolution 64(6):1594-1606

Lounibos LP, Escher RL, Duzak D, Martin EA (1996) Body size, sexual receptivity and larval cannibalism in relation to protandry among Toxorhynchites mosquitoes. Oikos 77(2):309-316

Mateo JM (2010) Self-referent phenotype matching and long-term maintenance of kin recognition. Anim Behav 80(5):929-935
Maurer E, Sih A (1996) Ephemeral habitats and variation in behaviour and life history: comparisons of sibling salamander species. Oikos 76:337-349

Michaud JP (2003) A comparative study of larval cannibalism in three species of ladybird. Ecol Entomol 28(1):92-101

Mock DW, Parker GA (1998) Siblicide, conflict and the evolutionary limits of selfishness. Anim Behav 56(1):1-10

Morse DH (2004) A test of sexual cannibalism models, using a sitand-wait predator. Biol J Linn Soc 81(3):427-437

Murphy GP, Dudley SA (2009) Kin recognition: competition and cooperation in Impatiens (Balsaminaceae). Am J Bot 96(11): 1990-1996

Myint O, Tsujimoto H, Ohnishi N, Takeyama T, Kohda M (2011) Mate availability affects female choice in a fish with paternal care: female counterstrategies against male filial cannibalism. J Ethol 29(1):153-159

Nam KB, Simeoni M, Sharp SP, Hatchwell BJ (2010) Kinship affects investment by helpers in a cooperatively breeding bird. Proc $\mathrm{R}$ Soc Lond B 277(1698):3299-3306

Newey P (2010) Not one odour but two: a new model for nestmate recognition. J Theor Biol 270(1):7-12

Nicolai A, Filser J, Briand V, Charrier M (2010) Seasonally contrasting life-history strategies in the land snail Cornu aspersum: physiological and ecological implications. Can J Zool 88(10):995-1002

Nishimura K, Isoda Y (2004) Erratum to "Evolution of cannibalism: referring to costs of cannibalism": [J Theor Biol 226:291-302]. J Theor Biol 228(2):291

O'Connor RJ (1978) Brood reduction in birds: selection for fratricide, infanticide and suicide? Anim Behav 26(1):79-96

Pervez A, Gupta AK, Omkar (2005) Kin recognition and avoidance of kin cannibalism by the larvae of co-occurring ladybirds: a laboratory study. Eur J Entomol 102(3):513-518

Pfennig D, Frankino W (1997) Kin-mediated morphogenesis in facultatively cannibalistic tadpoles. Nature 362:836-838

Polis G (1981) The evolution and dynamics of intraspecific predation. Annu Rev Ecol Syst 12:225-251

Queller DC (1994) Genetic relatedness in viscous populations. Evol Ecol 8(1):70-73

Ramsay G (1990) Mantodea (Insecta) with a review of aspects of functional morphology and biology. Fauna N Z 19:1-96

Roberts JA, Taylor PW, Uetz GW (2003) Kinship and food availability influence cannibalism tendency in early-instar wolf spiders (Araneae: Lycosidae). Behav Ecol Sociobiol 54:416-422

Rousset F, Roze D (2007) Constraints on the origin and maintenance of genetic kin recognition. Evolution 61(10):2320-2330

Rudolf VHW, Kamo M, Boots M (2010) Cannibals in space: the coevolution of cannibalism and dispersal in spatially structured populations. Am Nat 175(5):513-524

Samu F, Toft S, Kiss B (1999) Factors influencing cannibalism in the wolf spider Pardosa agrestis (Araneae, Lycosidae). Behav Ecol Sociobiol 45(5):349-354

Sergio F, Blas J, López L, Tanferna A, Díaz-Delgado R, Donázar JA et al (2011) Coping with uncertainty: breeding adjustments to an unpredictable environment in an opportunistic raptor. Oecologia 166(1):79-90

Sharell R (1971) New Zealand insects and their story. Collins, Auckland

Sharp SP, McGowan A, Wood MJ, Hatchwell BJ (2005) Learned kin recognition cues in a social bird. Nature 434(7037):1127-1130

Sherratt TN, Ruff SE, Church SC (1999) No evidence for kin discrimination in cannibalistic tree-hole mosquitoes (Diptera: Culicidae). J Insect Behav 12(1):123-132

Simons AM (2007) Selection for increased allocation to offspring number under environmental unpredictability. J Evol Biol 20(2):813-817 
Taylor PD (1992) Altruism in viscous populations-an inclusive fitness model. Evol Ecol 6(4):352-356

Tsutsui N (2004) Scents of self: the expression component of self/ non-self recognition systems. Ann Zool Fenn 41(6):713-727

West SA, Gardner A (2010) Altruism, spite, and greenbeards. Science 327(5971):1341-1344

West S, Murray MG, Machado C, Griffin A, Herre E (2001a) Testing Hamilton's rule with competition between relatives. Nature 409(6819):510-513
West SA, Murray MG, Machado CA, Griffin AS, Herre EA (2001b) Testing Hamilton's rule with competition between relatives. Nature 409(6819):510-513

Wise DH (2006) Cannibalism, food limitation, intraspecific competition, and the regulation of spider populations. Annu Rev Entomol 51:441-465 